\title{
Mediação Dialética com enfoque CTS/CTSA de temáticas de Segurança, Ambiente e Saúde na Educação Profissional de Nível Médio
}

\author{
Dialectical Mediation with STS/STSE approach of security environment and \\ health issues in middle level professional technical education
}

Felipe Sarmenghi Rangel${ }^{1}$; Jéssica Cristina S. Delcarro² ${ }^{2}$ Sidnei Quezada M. Leite ${ }^{3}$

1- Professor da Educação Profissional e Tecnológica, Programa de Pós-graduação em Educação em Ciências e Matemática, IFES, Vitória, Espírito Santo, Brasil - Email: felipe @ifes.edu.br - https://orcid.org/0000-0002-5004-2837

2- Professora de Ciências Biológicas, Programa de Pós-graduação em Educação em Ciências e Matemática, IFES, Vitória, Espírito Santo, Brasil - E-mail: jessica.delcarro@gmail.com - https://orcid.org/0000-0002-5004-2837

3- Professor da Educação Profissional e Tecnológica, Programa de Pós-graduação em Educação em Ciências e Matemática, IFES, Vitória, Espírito Santo, Brasil - E-mail: squezada@ifes.edu.br - https://orcid.org/0000-0003-0324-7685

\section{Recebido em 16/11/2018. Publicado em Dezembro/2019}

Palavras-chave:
Educação Profissional.
Metodologia de
mediação dialética.
Contextualização. Ensino
Médio. Prática
Educativa. SMS.

Keywords:

Professional Education. Dialectic Mediation. Contextualization. High School. Educational Practice. EnvironmentHealth-Safety.
RESUMO: O objetivo deste trabalho foi o de estudar os aspectos teóricos e metodológicos do desenvolvimento de uma intervenção pedagógica planejada na perspectiva da mediação dialética e contextualização. Tratou-se de uma investigação qualitativa sobre uma intervenção pedagógica, cujos dados foram produzidos a partir de observações praticantes, rodas de conversas, avaliações em grupo e individuais, fotografias, além de anotações feitas pelos estudantes. A prática foi realizada no contexto da educação profissional de nível médio, nos anos de 2011 a 2016, durante 2 meses de cada ano, envolvendo estudantes do ensino público federal de Aracruz, Espírito Santo, Brasil. A análise metodológica feita com base na contextualização e mediação dialética evidenciou momentos de resgatar, problematizar, sistematizar e produzir, os quais promoveram abrangência dos conteúdos e aspectos transversais, englobando a formação cidadã e profissional. O desenvolvimento da intervenção pedagógica demonstrou as potencialidades para abordagem dos conteúdos programáticos com diálogos diferentes saberes epistemológicos e suas aplicações nas diversas situações reais ligadas ao cotidiano escolar e profissional.

ABSTRACT: The objective of this work was to study the theoretical and methodological aspects of the development of a planned pedagogical intervention in the perspective of dialectical mediation and contextualization. It was a qualitative investigation about a pedagogical intervention, whose data were produced from practicing observations, conversation wheels, group and individual evaluations, photographs, besides notes made by the students. The practice was carried out in the context of high school professional education, from 2010 to 2017, during 2 months of each year, involving students from the federal public education of Aracruz city, Espírito Santo State, Brazil. The methodological analysis based on the contextualization and dialectical mediation revealed moments of rescuing, problematizing, systematizing and producing, which promoted the comprehensiveness of contents and cross-cutting aspects, encompassing citizen and professional training. The development of the pedagogical intervention demonstrated the potentialities to approach the programmatic contents allowing the dialogue between the epistemological knowledge and its applications in the various real situations related to the school and professional daily life. 


\section{INTRODUÇÃO}

A disciplina de Segurança, Meio Ambiente e Saúde comparece em uma boa parte dos itinerários formativos dos cursos de ensino técnico de nível médio, considerando o Catálogo Nacional de Cursos Técnicos (CNCT) organizados em treze eixos tecnológicos (BRASIL, 2016). Ao todo, são 227 cursos que apresentam respectivas cargas horárias mínimas; perfil profissional de conclusão; infraestrutura mínima requerida; campo de atuação; ocupações associadas à Classificação Brasileira de Ocupações (CBO); normas associadas ao exercício profissional; e possibilidades de certificação intermediária em cursos de qualificação profissional, de formação continuada em cursos de especialização e de verticalização para cursos de graduação no itinerários formativo. A disciplina tem por objetivo abordar, entre outras coisas, a interpretação da legislação vigente e normas técnicas referentes aos processos produtivos, manutenção, saúde e segurança no trabalho, qualidade e ao ambiente. O CNCT é um instrumento que disciplina a oferta de cursos de educação profissional técnica de nível médio, para orientar as instituições, estudantes e a sociedade em geral. É um referencial para subsidiar o planejamento dos cursos e correspondentes qualificações profissionais e especializações técnicas de nível médio (BRASIL, 2016).

No caso do curso Técnico em Química [integrado ao ensino médio] do campus Aracruz do Instituto Federal do Espírito Santo, a disciplina de Segurança, Meio Ambiente e Saúde é ofertada no primeiro ano, dos quatro anos do itinerário formativo (IFES, 2009). Um estudo prévio realizado com professores da instituição de ensino evidenciou que nos primeiros anos de 2011 a 2016, a disciplina se configurava eminentemente teórica. Entretanto, houve uma demanda de se introduzir práticas pedagógicas alternativas a fim de torná-la mais interessante para os estudantes. Além disto, um dos desafios é tornar as práticas pedagógicas dialogadas com outras disciplinas no itinerário formativo, isto é, realizar de fato interdisciplinaridade, considerando o contexto da educação profissional técnica integrada ao ensino médio (BRASIL, 2007; PEREIRA e PASSOS, 2012; VIEIRA e VIEIRA, 2016).

Durante as reuniões do grupo de pesquisa, surgiram alguns questionamentos que balizaram a construção deste estudo. Por exemplo, de que maneira uma prática pedagógica baseada na perspectiva freiriana poderia se articular com os conteúdos programáticos da disciplina de forma contextualizadora? De que maneira uma proposta baseada em mediação dialética [freiriana] poderia ser articulada em práticas realizadas num contexto da educação profissional de nível médio? De que maneira seria possível introduzir uma práxis educativa freiriana, tendo em vista a formação de indivíduos ativos socialmente, críticos e emancipados, contribuindo para a formação cidadã e profissional? 
Freire (2005) propõe uma abordagem temática em seu livro "Pedagogia do Oprimido", partindo de situações-limite que são dimensões desafiadoras [ou problemas], as quais emergem da atividade dos homens e que, para eles, nem sempre são percebidas como tais. Entretanto, o autor pondera que as situações não devem ser encaradas como barreiras insuperáveis, mas como oportunidades para mudanças, as quais podem ser verificadas e superadas com base nas próprias ações humanas de enfrentamento sobre a realidade. Portanto, no contexto escolar, é desejável que o educador incentive o desenvolvimento de uma percepção crítica dos estudantes [educandos] sobre essas situações para além daquilo que se mostra aparente.

Considerando a perspectiva de Freire (2011), a relação teórica e metodológica se estabelece a partir da prática educativa, a qual utiliza-se de instrumentos que abordem temáticas profundas, reflexivas, autônomas e de vasta dimensão existencial, primordialmente. Arnoni (2012) ressalta que, em termos processuais do planejamento da prática educativa, a partir dos fundamentos filosóficos da Lógica Dialética e da Ontologia do ser social na práxis educativa, vale compreender a Metodologia da Mediação Dialética (MMD), que valoriza a mediação dialético-pedagógica e a relação pedagógica entre o professor e o estudante, de modo a conferir dinamicamente a direção e o sentido da luta pela formação integral do professor e do estudante à prática educativa. Correia e Carvalho (2012) ressaltam que a práxis permite compreender a produção epistêmica e o ato de educar como práticas sociais, realizadas conforme as condições objetivas e subjetivas que homens e mulheres encontram no decorrer da história que protagonizam.

De acordo com Arnoni (2012), a organização metodológica do conteúdo do ensino é formada por quatro etapas, a saber: (1) Resgatar: por meio de diferentes linguagens e pautado no conceito a ser desenvolvido, o professor elabora a atividade educativa para investigar as ideias iniciais dos estudantes sobre o conceito a ser ensinado; (2) Problematizar: por meio de diferentes linguagens e a partir da análise das respostas obtidas na etapa anterior, o professor elabora a atividade educativa capaz de levar o estudante a perceber a diferença/contradição entre suas ideias iniciais e o conceito desenvolvido pelo professor, e de gerar motivações que direcionam investigações na busca de novas relações. O professor aplica a atividade problematizadora junto aos estudantes, analisa as respostas obtidas e, a partir dela, planeja a etapa seguinte; (3) Sistematizar: por meio de diferentes linguagens e a partir da análise das respostas obtidas na etapa anterior, o professor elabora a atividade educativa para discutir a questão-problema, por meio das informações conceituais e, assim, potencializar a superação das ideias iniciais e a elaboração de síntese cognitiva; (4) Produzir: por meio de diferentes linguagens e a partir da análise das respostas obtidas na etapa anterior, o professor elabora a 
atividade educativa que permita ao estudante expressar a síntese cognitiva elaborada ao vivenciar as etapas da MMD.

Ao contrário do que defendemos, de acordo com Santos (2007), alguns professores consideram contextualização sinônimo de abordagem de situações do cotidiano, no sentido de descrever, nominalmente, o fenômeno com a linguagem científica. No entanto, em geral essa abordagem é realizada sem explorar as dimensões sociais nas quais os fenômenos estão inseridos. Considerando a perspectiva do movimento Ciência, Tecnologia, Sociedade e Ambiente (CTS/CTSA), que consideram as reflexões sobre a consequências ambientais (ANGOTTI e AUTH, 2001) além das interrelações entre ciência-tecnologia-sociedade. Há um grupo de investigadores que enfatizam também as implicações ambientais usando a denominação CTSA, em vez de CTS (SANTOS e AULER, 2011). De acordo com os autores, o movimento CTS incorporou a vertente ambiental à tríade CTS, passando a denominar CTSA, na tentativa de resgatar o papel da educação ambiental (EA) do movimento inicial de CTS. Como destaca Santos (2007), uma proposta curricular de CTS pode ser vista como uma integração entre educação científica, tecnológica e social, em que conteúdos científicos e tecnológicos são estudados juntamente com a discussão de seus aspectos históricos, éticos, políticos e socioeconômicos (LÓPEZ e CEREZO, 1996). Neste caso, o objetivo principal dos currículos CTS/CTSA é o desenvolvimento da capacidade de tomada de decisão, razão pela qual o movimento CTSA acrescenta aos propósitos de CTS a ênfase em questões ambientais, visando também a promoção da educação ambiental. Neste trabalho utilizamos a sigla CTS/CTSA para agregar o movimento como todo [CTS+A], englobando a perspectiva CTSA.

O objetivo deste trabalho foi o de estudar os aspectos teóricos e metodológicos do desenvolvimento de uma intervenção pedagógica planejada na perspectiva da mediação pedagógica-dialética e contextualização. Foram considerados aspectos da prática educativa, relação entre teoria e prática e potencialidades para uma educação CTS/CTSA.

\section{METODOLOGIA}

O presente trabalho é parte de um estudo maior em desenvolvimento que visa compreender, entre outras coisas, as transformações pedagógicas de 2011 até 2016. Esta investigação qualitativa foi planejada à luz de Gil (2014) sobre uma intervenção pedagógica que foi planejada com base na proposta da mediação dialético-pedagógica (ARNONI, 2012), considerando o contexto do ensino de segurança, meio ambiente e saúde na educação profissional de nível médio. Os dados foram produzidos a partir de observação participante, rodas de conversas, avaliações e anotações feitas pelos estudantes nos diários de bordo, além 
de leituras de trabalhos da área da educação. O estudo foi realizado com base em dados coletados em práticas aplicadas em 09 turmas do curso técnico em química [integrado ao ensino médio], no intervalo de 06 anos [2011 - 2016], totalizando 372 alunos participantes. No quadro 1 está apresentado um resumo das técnicas e instrumentos de coleta de dados empregados durante a investigação da intervenção escolar.

Quadro 1 - Resumo das técnicas e instrumentos de coleta de dados empregados durante a investigação das práticas realizadas de 2011 a 2016, numa escola pública de ensino técnico de nível médio da cidade de Aracruz, Espírito Santo, Brasil.

\begin{tabular}{|c|l|l|}
\hline Investigação & Técnicas & Instrumentos \\
\hline \multirow{2}{*}{$\begin{array}{c}\text { Investigação } \\
\text { Qualitativa }\end{array}$} & Observações & Anotações no diário de bordo do investigador. \\
\cline { 2 - 3 } Tipo: Estudo de Caso & Inquéritos & Rodas de conversas mediadas por perguntas. \\
\cline { 2 - 3 } & Imagens & Fotografias como registro da prática. \\
\cline { 2 - 3 } & Relatos escritos & Anotações no diário de bordo do estudante. Avaliações escritas. \\
\hline
\end{tabular}

Fonte: Adaptação dos autores.

Para planejar a intervenção escolar, nos baseamos na perspectiva da Metodologia de Mediação Dialética (MMD) baseadas em Freire (2005), Arnoni (2012), Saul (2014) e Correia e Carvalho (2012). No quadro 2 está apresentado os 4 (quatro) momentos da MMD, não necessariamente consecutivos, escritos com base nesses autores. A MMD é uma proposição metodológica que operacionaliza o método dialético e a concepção de mundo, com base na dialética e ontologia do ser social. Teoria e método possibilitam a interpretação da realidade e constituem os fundamentos que informam o processo de passagem para a prática, pela pesquisa teórica da questão metodológica, reiterando o vínculo entre os fundamentos teóricos e a metodologia, evitando que a questão metodológica caia na esteira estigmatizada de um trabalho secundário. Buscamos nos aproximar da perspectiva de Freire (2005), buscando diálogos com a abordagem temática descrita no capítulo 3 do livro Pedagogia do Oprimido, parte de situações-limite que são dimensões desafiadoras [ou problemas] que emergem da atividade dos homens e que, para eles, nem sempre são percebidas como tais.

A intervenção pedagógica foi realizada sempre no primeiro semestre de cada ano, da disciplina de Segurança, Meio Ambiente e Saúde do curso Técnico em Química [integrado ao ensino médio], de um campus do Instituto Federal do Espírito Santo, situado na cidade de Aracruz, Estado do Espírito Santo, Brasil. Os dados emergiram de uma prática pedagógica para abordar Equipamentos de Proteção Individual, Primeiros Socorros de Saúde e Aula de Campo numa Estação de Tratamento de Água, realizada no período de 2011 a 2016, sendo aprimorada a cada ano, envolvendo estudantes com idade entre 15 a 18 anos. Para desenvolver o estudo a partir de dados históricos, procurou-se seguir todas as recomendações realizadas pelo Comitê 
de Ética em Pesquisa/CONEP do Instituto Federal do Espírito Santo. A identidade dos sujeitos foi preservada para evitar a exposição deles.

Quadro 2 - Metodologia de Mediação Dialética (MMD) aplicada na construção de uma intervenção pedagógica, perpassando 4 (quatro) momentos com base em Arnoni (2012), não necessariamente consecutivos.

\begin{tabular}{|c|c|c|}
\hline Momentos & $\begin{array}{l}\text { Situação } \\
\text { Pedagógica }\end{array}$ & Contexto \\
\hline I & Resgatar & $\begin{array}{l}\text { Por meio de diferentes linguagens e pautado no conceito a ser } \\
\text { desenvolvido, o professor elabora a atividade educativa para investigar } \\
\text { as ideias iniciais dos estudantes sobre o conceito a ser ensinado, aplica- } \\
\text { a junto aos estudantes, analisa as respostas obtidas e, a partir dela, } \\
\text { planeja a etapa seguinte; }\end{array}$ \\
\hline II & Problematizar & $\begin{array}{l}\text { Por meio de diferentes linguagens e a partir da análise das respostas } \\
\text { obtidas na etapa anterior, o professor elabora a atividade educativa } \\
\text { capaz de levar o estudante a perceber a diferença/contradição entre suas } \\
\text { ideias iniciais e o conceito desenvolvido pelo professor, e de gerar } \\
\text { motivações que direcionam investigações na busca de novas relações. } \\
\text { O professor aplica a atividade problematizadora junto aos estudantes, } \\
\text { analisa as respostas obtidas e, a partir dela, planeja a etapa seguinte; }\end{array}$ \\
\hline III & Sistematizar & $\begin{array}{l}\text { Por meio de diferentes linguagens e a partir da análise das respostas } \\
\text { obtidas na etapa anterior, o professor elabora a atividade educativa para } \\
\text { discutir a questão-problema, por meio das informações conceituais e, } \\
\text { assim, potencializar a superação das ideias iniciais e a elaboração de } \\
\text { sínteses cognitivas. O professor aplica a atividade sistematizadora } \\
\text { junto aos estudantes, analisa as respostas obtidas e, a partir dela, } \\
\text { planeja a etapa seguinte; }\end{array}$ \\
\hline IV & Produzir & $\begin{array}{l}\text { Por meio de diferentes linguagens e a partir da análise das respostas } \\
\text { obtidas na etapa anterior, o professor elabora a atividade educativa que } \\
\text { permita ao estudante expressar as sínteses cognitivas elaboradas ao } \\
\text { vivenciar as etapas da MMD. O professor aplica a atividade junto aos } \\
\text { estudantes, analisa suas respostas e compara-as com a produção da 1a } \\
\text { etapa, para verificar se houve superação das ideias iniciais dos } \\
\text { estudantes no conceito elaborado. Se a análise demonstrar que houve } \\
\text { superação, o Produzir torna-se imediatamente um novo ponto de } \\
\text { partida, o Resgatar caso a análise demonstre que não houve superação, } \\
\text { é recomendável ao professor planejar novamente a prática educativa. }\end{array}$ \\
\hline
\end{tabular}

Fonte: Adaptação dos autores.

Neste trabalho, utilizamos o paradigma interpretativista e procuramos nos limitar a apresentar uma análise fenomenológica da intervenção pedagógica (Gil, 2009, p. 29, p. 95). Os aspectos teóricos e metodológicos foram analisados com base em Freire $(2004 ; 2005)$ e Delizoicov, Angotti e Pernambuco (2002) e, posteriormente, Solino e Gehlen (2014), Maestrelli e Torres (2014) e Caetano, Leite e Rosa (2017). As práticas educativas e a relação teoria-prática foram analisadas na proposta por Ferreira (2015), Saul (2014) e Freire (2011, 2005). Também foram analisados os aspectos sociofilosóficos à luz da educação CTS/CTSA na perspectiva de Paulo Freire baseados em Auler (2011), Santos (2004), e Santos e Auler (2011). 


\section{ASPECTOS METODOLÓGICOS DA EDUCAÇÃO CTS/CTSA}

\subsection{Etapa I: Resgatar}

De acordo com o dicionário da língua portuguesa Aurélio, "contextualização" é a ação de estabelecer um contexto para determinada coisa, normalmente com o intuito de explicar os motivos ou características precedentes de uma situação. Entretanto, a ideia de contextualização entrou na seara de debates da reforma da educação básica de 1996, a partir da Lei de Diretrizes e Bases da Educação (LDB) (BRASIL, 1996), cujo foco é a compreensão dos conhecimentos para uso cotidiano. Posteriormente, o conceito foi mais debatido nos Parâmetros Curriculares Nacionais da Educação Básica (PCN) (BRASIL, 1998). De acordo com esses documentos, a organização curricular dos cursos da educação básica deve abranger conteúdos de ensino de modo contextualizado, aproveitando sempre as relações entre conteúdos e contexto para dar significado ao aprendido, estimular o protagonismo do estudante e estimulá-lo a ter autonomia intelectual. Mais recentemente, as Diretrizes Curriculares Nacionais para a Educação Básica (DCNEB) (BRASIL, 2013) que preconizam uma educação com qualidade social, tendo como foco práticas contextualizadoras que perpassem pela relação educação-tecnologia-ciênciacultura, direitos humanos, sustentabilidade, trabalho-educação e pesquisa-educação.

Para estudar a Gestão Integrada de Segurança, Meio Ambiente e Saúde (SMS) que aborda as Normas Regulamentadoras (NR) da Segurança que tratam do uso de Equipamento de Proteção individual (EPI - NR 06), da Comissão Interna de Prevenção de Acidentes (CIPA NR 05) e da Prevenção de Riscos Ambientais (PPRA - NR 09), inicialmente realiza-se provocações na tentativa de enfatizar a importância do estudo para a vida profissional. Neste sentido, foram realizadas rodas de conversas iniciais a partir de práticas lúdicas, como por exemplo a exibição de fotografias do mundo do trabalho evidenciando situações de perigo. A ideia era que os estudantes pudessem reconhecer situações de risco, diferentes tipos de riscos (químicos, físicos e biológicos), e a necessidade de prevenção de acidentes. Na Figura 1 está mostrado um mosaico com algumas fotografias e cartoons, evidenciando potenciais riscos físicos, químicos e biológicos durante esta etapa da intervenção pedagógica.

Para realizar uma contextualização inicial, a partir do mosaico exibido na Figura 1, percebe-se algumas situações de risco físico, químico e biológico existente no mundo do trabalho. Por exemplo, quando se trabalha em áreas abertas, é possível encontrar animais peçonhentos como cobras venenosas, aranhas e outras situações de risco como áreas alagadas contendo contaminação de leptospirose. Também vale ressaltar os trabalhos técnicos feitos em manutenção de corrente elétrica que às vezes pode ocasionar em choques com lesões. Por fim, ressaltamos as áreas contendo risco de incêndio por estoque de substâncias inflamáveis. 


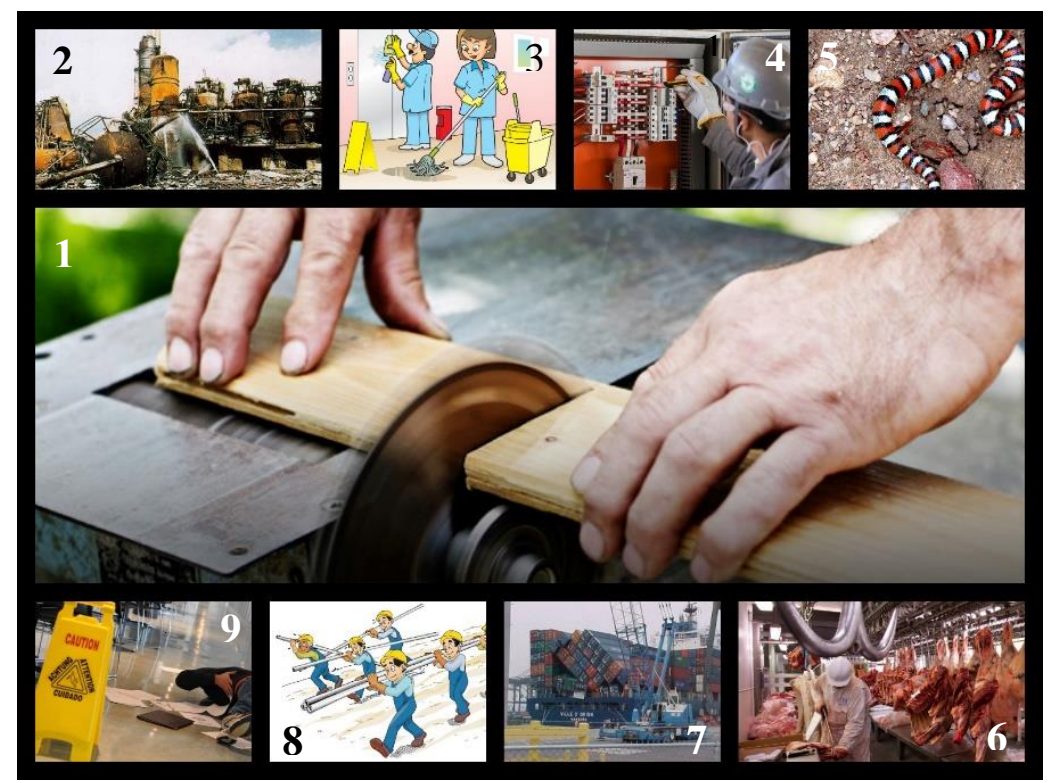

Figura 1 - Mosaico de fotografias e cartoons evidenciando potenciais riscos físicos, químicos e biológicos durante esta etapa da intervenção pedagógica.

Fonte: Adaptação dos autores a partir dos seguintes acessos:

(1) Disponível em: https://www.causaoperaria.org.br/acervo/blog/2017/11/23/precarizacao-do-trabalho-geraacidentes-e-mortes/\#.XMAvP5NKi1t

(2) Disponível em https://slideplayer.com/slide/261833/

(3) Disponível em https://pt.slideshare.net/robsonqsmsrs/cartilha-riscos-limpeza

(4) Disponível em https://www.metropoles.com/distrito-federal/distrito-federal-registra-alta-nos-acidenteseletricos-em-2016

5) Disponível em https://betaeducacao.com.br/tag/prevencao-de-acidentes/page/2

6) Disponível em https://www.vice.com/es/article/vdkvma/muerte-y-mugre-asi-es-trabajar-en-un-mataderofraudulento-en-holanda-596

7) Disponível em http://nrfacil.com.br/blog/?p=1450

8) Disponível em http://bombeiroswaldo.blogspot.com/2016/03/organizacao-e-conteudo-do-trabalho-para.html

9) Disponível em https://blog.sst.com.br/entenda-quais-sao-os-3-acidentes-de-trabalho-mais-comuns/

Ao olhar para as Diretrizes Curriculares Nacionais para o Ensino Médio, de acordo com artigo 50 "o ensino médio, em todas as suas formas de oferta e organização", baseia-se em: [...] "VIII - integração entre educação e as dimensões do trabalho, da ciência, da tecnologia e da cultura como base da proposta e do desenvolvimento curricular” (BRASIL, 2013). Neste sentido, a contextualização passa a ser uma estratégia importante para a realização de um ensino médio considerando estas características relacionadas ao mundo do trabalho. O princípio da contextualização se constitui em um dos fundamentos pedagógicos da reforma do ensino médio implantada no Brasil no final dos anos de 1990 (DOMINGUES et al., 2000). A introdução de ações contextualizadoras foi apoiada por pensadores de uma educação crítica e preocupados com uma educação ampla, questionadora e de qualidade.

Na Figura 2 mostra um mosaico contendo dados estatísticos de acidentes do trabalho construído com base na Lei Federal № 8.213, de 24 de julho de 1991 (BRASIL, 1991). Uma das formas de sensibilizar os estudantes sobre a temática de acidentes do trabalho é pela exibição de dados estatísticos sobre acidente no trabalho. De acordo com a lei, acidente do 
trabalho é o que ocorre pelo exercício do trabalho a serviço da empresa, ou ainda pelo exercício do trabalho dos segurados especiais, provocando lesão corporal ou perturbação funcional que cause a morte, a perda ou redução da capacidade para o trabalho permanente ou temporária.

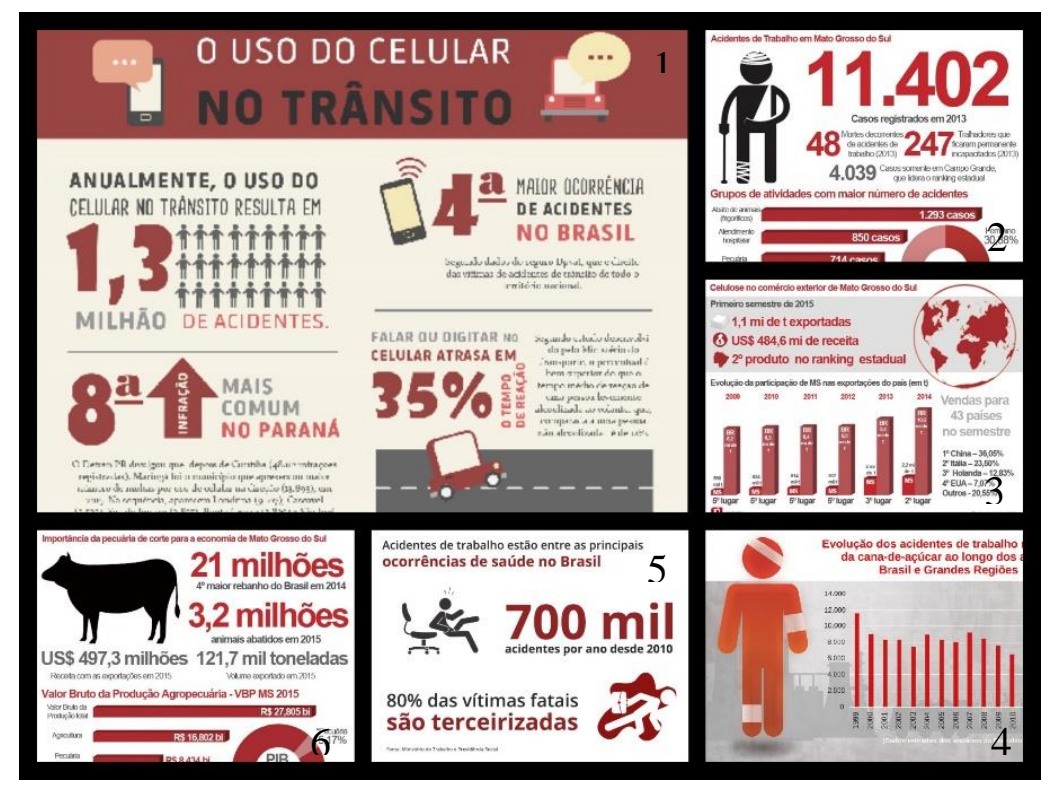

Figura 2 - Mosaico contendo fotografias de dados estatísticos de acidentes do trabalho baseado na Lei Federal № 8.213, de 24 de julho de 1991 .

Fonte: Adaptação dos autores a partir dos seguintes acessos:

1) Disponível em http://fetropar.org.br/o-uso-do-celular-no-transito-2/

2) Disponível em http://g1.globo.com/mato-grosso-do-sul/noticia/2015/11/vitimas-lutam-para-superar-traumasde-acidentes-de-trabalho-em-ms.html

3) Disponível em http://g1.globo.com/mato-grosso-do-sul/noticia/2015/08/investimento-de-r-157-bilhoes-emcelulose-gera-expectativa-em-ms.html

4) Disponível em https://revistarpanews.com.br/ed/73-edicao2015/edicao-188/1548-por-que-ainda-ocorremacidentes-de-trabalho-no-ctt-das-usinas

5) Disponível em http://www.radiodocaminhoneiro.com.br/noticia/21671/dia-28-de-abril---dia-mundial-emmemoria-das-vitimas-de-acidente-de-trabalho

6) Disponível em http://g1.globo.com/mato-grosso-do-sul/noticia/2016/02/cuidado-sanitario-na-producao-decarne-vai-do-campo-ate-o-mercado.html

Por meio de dados estatísticos sobre ocorrência dos acidentes de trabalho foi possível contextualizar sobre as questões de prevenção e ocorrência dos acidentes, além de propiciar o estudo dos principais tipos de acidentes. Foram avaliados os grupos de atividades com maiores índices de acidentes, os potenciais impactos de condições inseguras que potencializam os acidentes de trânsito, como a distração causada pelo uso dos celulares durante o ato de dirigir. Os motoristas profissionais estão entre os grupos de trabalhadores que sofrem mais acidentes no Brasil, enquanto os trabalhos que envolvem agricultura estão entre os mais vulneráveis e propício a acidentes.

De acordo com o PCN do Ensino Médio (BRASIL, 2000), as práticas educacionais devem abranger, de forma combinada, o desenvolvimento de conhecimentos práticos, contextualizados, que respondam às necessidades da vida contemporânea, e o desenvolvimento 
de conhecimentos mais amplos e abstratos, que correspondam a uma cultura geral e a uma visão de mundo. Estas ideias também são corroboradas no documento das Diretrizes Curriculares Nacionais (BRASIL, 2013), incluindo além das práticas de contextualização, as práticas de interdisciplinaridade como eixo estruturantes no ensino médio, a partir da inserção de situações do cotidiano com vistas a promover conexões entre saberes escolares e não escolares. Visando apresentar as principais interações interdisciplinares entre os conteúdos de segurança do trabalho e disciplinas tradicionais do currículo do Ensino Médio, construiu-se um diagrama mental para o módulo de Segurança do Trabalho de SMS, conforme é mostrado na Figura 3.

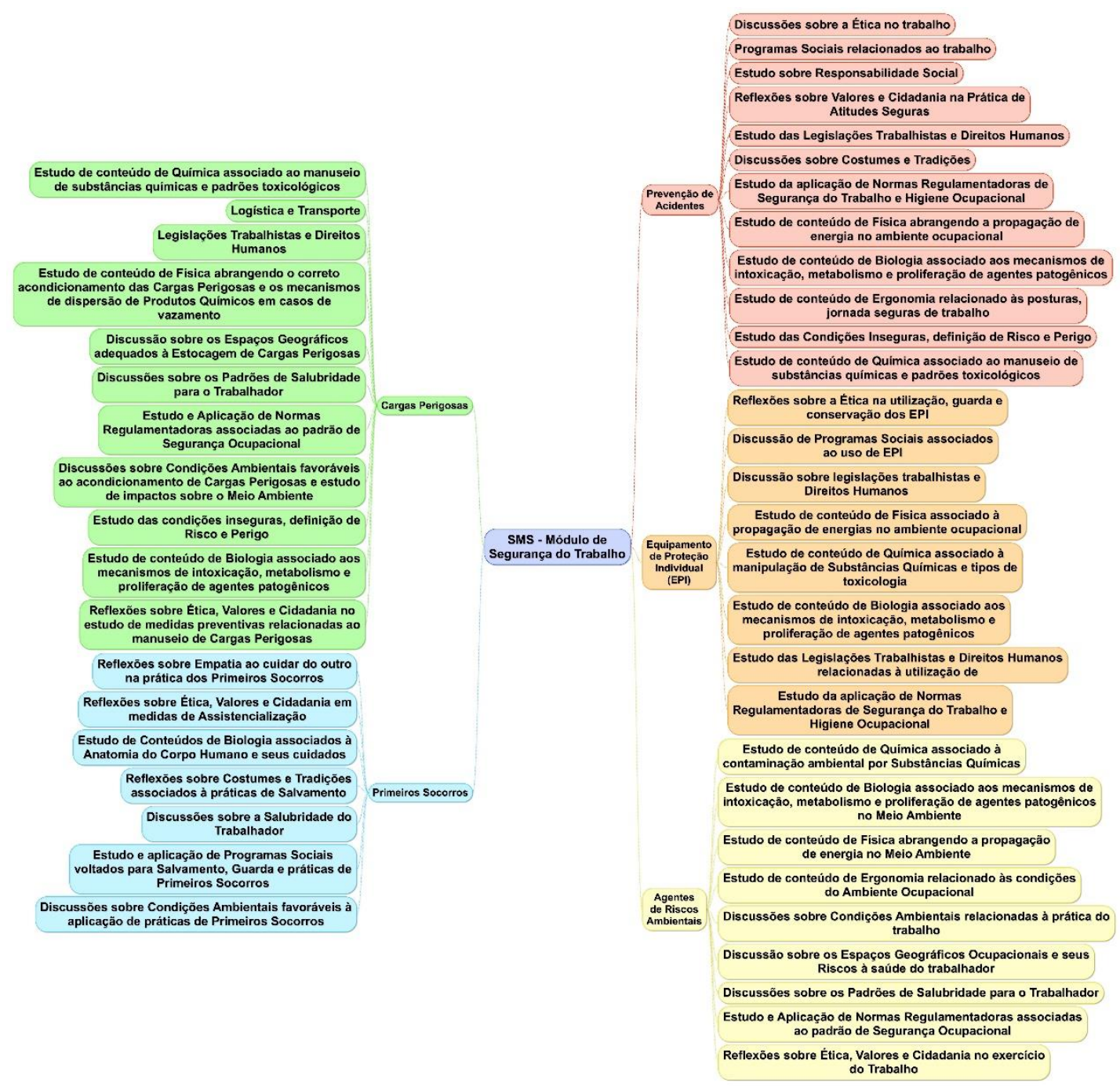

Figura 3 - Diagrama mental relacionando as potencialidades de abrangência de conteúdos produzidos durante esta etapa da disciplina.

Fonte: Adaptação dos autores.

No caso do diagrama mental, assuntos abordados em sala de aula são organizados em 05 categorias de análise de temas, sendo elas: Prevenção de Acidentes, Equipamentos de Proteção Individual (EPI), Agentes de Riscos Ambientais, Cargas Perigosas e Primeiros Socorros. Os assuntos abordados em cada classe visam a contextualização dos conhecimentos específicos, a interdisciplinaridade e transdisciplinaridade, além da confluência de saberes 
científicos e populares, ao estudar, por exemplo, como a análise das condições ambientais favoráveis ao acondicionamento de cargas perigosas podem mitigar possíveis impactos à saúde do trabalhador ao meio ambiente.

Arnoni (2012) alerta que [...] "compreender o mundo como totalidade complexa e dinâmica, depreende-se a intencionalidade de o capital propor um "ciclo perfeito" para direcionar a ação das diferentes instâncias sociais na educação escolar, do nível universal ao local e novamente ao universal”. No âmbito da sala de aula, vale olhar a relação entre a proposta de aula como práxis educativa e o contexto escolar regido pelo modelo capitalista. Neste sentido, o autor ressalta que entender a educação escolar como práxis educacional impõe o entendimento que sua função é a de organizar a sociedade e, assim, depreendem-se basicamente duas possibilidades, a busca da emancipação política como proposta oficial e a busca da emancipação humana.

A interdisciplinaridade é entendida por Almeida e Biajone (2007) como uma importante atribuição profissional dos professores em que o conhecimento contextualizado é apresentado de maneira a relacionar conteúdo programático de uma dada disciplina aos conteúdos de outras disciplinas. O módulo de Segurança de Trabalho da disciplina de SMS, ao tratar da Prevenção dos Acidentes, da avaliação dos Agentes de Riscos Ambientais, da operação de atividades com Cargas Perigosas, da utilização de Equipamento de Proteção Individual (EPI) e das práticas de Primeiros Socorros relaciona o conteúdo de tais assuntos com os conhecimentos prévios de disciplinas curriculares como Física, Química e Biologia, por exemplo.

Ao estudar características e especificidades do manuseio, acondicionamento e toxicologia das substâncias químicas visando a prevenção de acidentes, os estudantes relacionam os conteúdos básicos da Química, como, por exemplo o peso molecular, acidez e alcalinidade, corrosão e irritação de tecidos e matérias, entre outros. O documento do PCN do ensino médio, nas recomendações específicas para a área de Ciências Naturais e Matemática, apresenta tópicos relativos ao princípio da contextualização ao qual abrange a inclusão de temas que englobem as interrelações entre ciência e tecnologia. Além disso, são listados, para essa área de conhecimento, competências e habilidades relativas à contextualização sociocultural. Posteriormente, a recomendação de ações pedagógicas contextualizadoras também irá aparecer nos documentos nas Orientações Curriculares Nacionais para o Ensino Médio (BRASIL, 2006) cujos documentos também preconizam a contextualização e a interdisciplinaridade como eixos centrais organizadores das dinâmicas interativas no ensino de diferentes disciplinas. Entretanto, Santos (2007) ressalta que muitos professores tem a compreensão de que a simples menção do cotidiano já significa contextualização. Mas o autor justifica que [...] “essa aparente 
contextualização é colocada apenas como um pano de fundo para encobrir a abstração excessiva de um ensino puramente conceitual, enciclopédico, de cultura de almanaque". Nessa concepção, complementa o autor, são adicionados cada vez mais conteúdos ao currículo, como se o conhecimento isolado por si só fosse a condição de preparar os estudantes para a vida social.

Santos (2007) também cita em outra concepção em voga é aquela na qual a contextualização significa um método de ensino que promove a motivação e melhora a aprendizagem. Neste trabalho, buscamos produzir uma análise sobre esta ótica, embora tenhamos a concordância de que a simples inclusão de questões do cotidiano pode não implicar a discussão de aspectos relevantes para a formação do estudante enquanto cidadão ou não motivar suficientemente os estudantes para se interessar por ciências.

Entretanto, quando a prática e feita de forma dialética, nos aproximando da perspectiva freiriana, ao propor se discutir os conteúdos a partir de situações problemáticas reais e buscar o conhecimento necessário para entendê-las e procurar solucioná-las. Ao assumir uma abordagem temática que, à luz da perspectiva de Paulo Freire, vise a mediação dos saberes escolares, científicos e populares, partimos de uma educação problematizadora, de caráter reflexivo, de arguição da realidade, na qual o diálogo começa a partir da reflexão sobre contradições básicas de situações existenciais, consubstanciando-se na educação para a prática da liberdade (FREIRE, 2011). Inspirados por Freire (2005), buscamos assumir o papel central do princípio da contextualização na formação da cidadania implicará a necessidade da reflexão crítica e interativa sobre situações reais e existenciais para os estudantes. Buscou-se promover o desenvolvimento de atitudes e valores aliados à capacidade de tomada de decisões responsáveis diante de situações reais. Por isso, a educação contextualizada, fundando-se numa relação dialógica entre o currículo e o contexto local, estudando a realidade que se conhece por vivência, permite que os professores e estudantes compreendam e assimilem os conceitos, pois é a realidade que passa a adquirir sentido (KRAUS, EGLER e COSTA, 2017).

De acordo com Kraus, Egler e Costa (2017), a prática social e a formação politizada podem contribuir para a produção de uma educação contextualizada, um vez que podem suprir a deficiências de conteúdos produzidas ao longo da vida de estudo, incluindo a dimensão da realidade local/regional [e atores], promovendo uma visão mais ampliada e crítica em comparação com práticas pedagógicas tradicionais. Por isso, buscamos desenvolver ações voltadas para uma educação contextualizada, promovendo a produção de saberes escolares a partir de diálogos entre escola e mundo do trabalho, perpassando por um viés das políticas de segurança, ambiente e saúde. 


\subsection{Etapa II: Problematizar}

A segunda etapa da intervenção pedagógica consistiu no reconhecimento do contexto e as relações entre o conteúdo de equipamentos de proteção, primeiros socorros e estação de tratamento de água, e suas relações com a temática guarda-chuva de Segurança, Meio Ambiente e Saúde. Neste trabalho, nos limitamos a discutir o bloco de conteúdos programáticos que trata da segurança do trabalho. No quadro 3 está apresentada uma lista de vídeos utilizados em sala de aula. Foram apresentados documentários que abordaram exibidas a utilização de EPI, com a introdução de alguns conceitos básicos sobre a proteção e projeto de prevenção de acidentes numa indústria. A identificação dos principais agentes de riscos ambientais, com exemplos reais de transporte de substâncias químicas, apresentação de rótulos de riscos, algumas práticas de primeiros socorros, inclusive com relatos de socorristas (quadro 3).

Quadro 3 - Uma lista de documentários contextualizadores utilizados em sala de aula para discutir segurança do trabalho.

\begin{tabular}{|l|l|}
\hline Temática Central & Referência do Vídeo \\
\hline \multirow{5}{*}{$\begin{array}{l}\text { Segurança do } \\
\text { Trabalho: }\end{array}$} & $\begin{array}{l}\text { Equipamentos de Proteção Individual: } \\
\text { https://www.youtube.com/watch?v=SrNn1Iir9Bs }\end{array}$ \\
\cline { 2 - 2 } & $\begin{array}{l}\text { Acidentes de Trabalho: } \\
\text { https://www.youtube.com/watch?v=XbZQbIlhWeY\&list=PLEFE87BB88B275CA6 }\end{array}$ \\
\cline { 2 - 2 } & $\begin{array}{l}\text { Agentes de Riscos Ambientais: } \\
\text { https://www.youtube.com/watch?v=IjOmG4MA6do }\end{array}$ \\
\cline { 2 - 2 } & $\begin{array}{l}\text { Prevenção de Acidentes: } \\
\text { https://www.youtube.com/watch?v=K5o9jm6Esn8\&index=8\&list=PLEFE87BB88B2 }\end{array}$ \\
\hline$\underline{75 C A 6}$ \\
\cline { 2 - 2 } & $\begin{array}{l}\text { Primeiros Socorros: } \\
\text { https://www.youtube.com/watch?v=1MtKw-uP1NM }\end{array}$ \\
\cline { 2 - 2 } & $\begin{array}{l}\text { Cargas perigosas: } \\
\text { https://www.youtube.com/watch?v=-UnYXwuk6PI }\end{array}$ \\
\hline
\end{tabular}

Fonte: Adaptação dos autores.

Na etapa II da intervenção pedagógica geralmente se realizava as apresentar situações reais em que os trabalhadores estão expostos e que, provavelmente, os estudantes já tinham vivenciados nas suas rotinas diárias. Nessa prática pedagógica, os estudantes foram desafiados a produzirem relatos sobre as situações apresentadas na exibição dos documentários a fim de externar as contradições locais/regionais a ponto de compreenderem a necessidade de produzirem novos conhecimentos, com os quais possam interpretar a situação mais adequadamente. Para isso, os debates foram promovidos a exibição de alguns documentários contextualizadores na tentativa de evidenciar de forma focada no mundo do trabalho relacionado à segurança do trabalho, saneamento e gestão hídrica (geral) e, por fím, gestão hídrica local - poluição e escassez. 
Além da problematização de casos específicos de segurança do trabalho, buscou-se a contextualização com temas transversais que estão associados à rotina ocupacional dos trabalhadores. Neste contexto, foram discutidos temas como as Consolidações das Leis do Trabalho (CLT) e os direitos humanos como aspectos políticos da abrangência transversal dos conteúdos de SMS, a responsabilidade social e a ética que envolve os trabalhos em equipe como características da vida em sociedade, a sustentabilidade financeira e os encargos trabalhistas como questões econômicas associadas à práticas ocupacionais de segurança do trabalho, entre outros. As potencialidades de abrangência de conteúdos produzidos durante esta etapa da está evidenciado em um diagrama mental apresentado pela Figura 4.
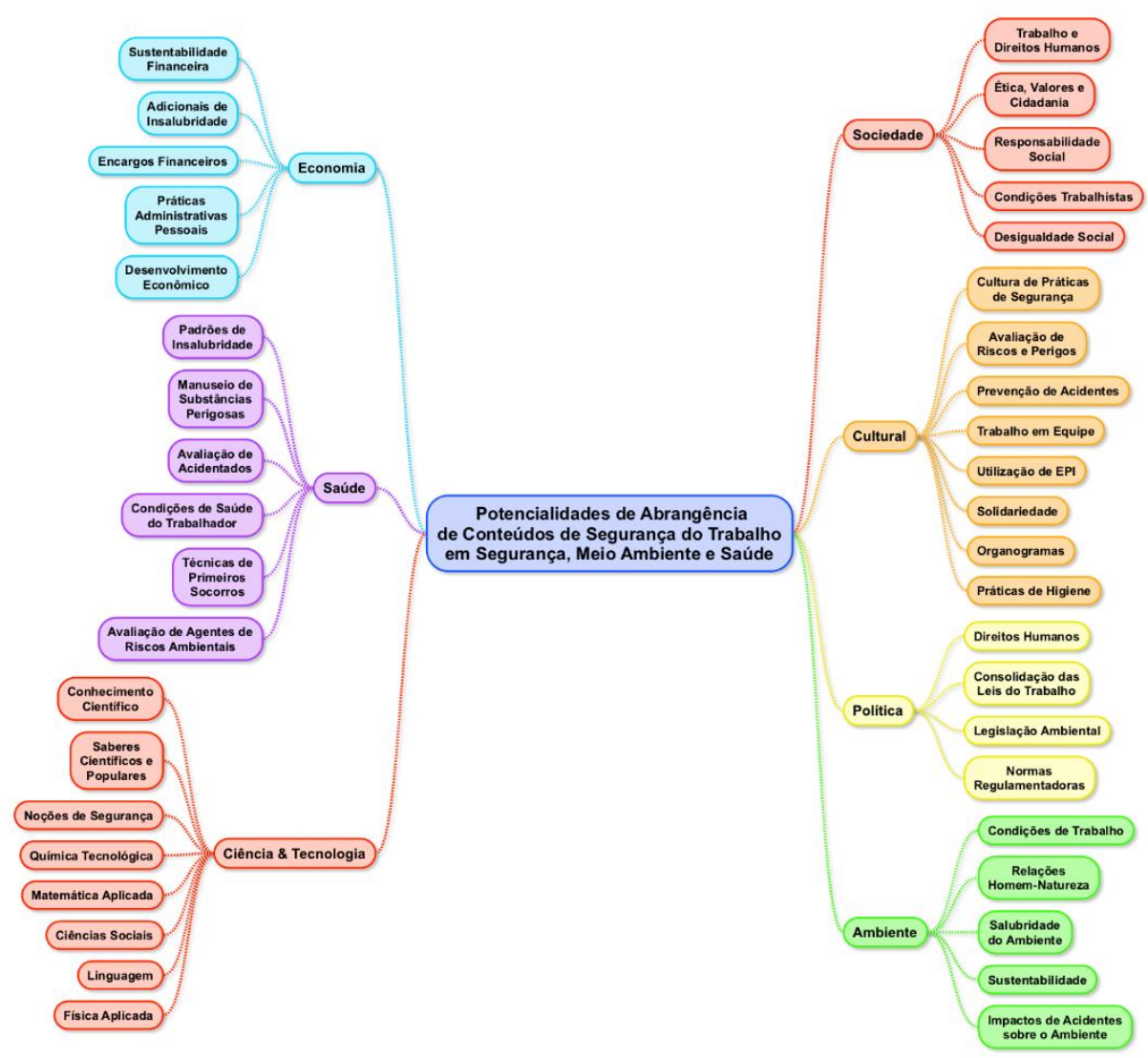

Figura 4 - Diagrama Mental com relacionando as potencialidades de abrangência de conteúdos produzidos durante esta etapa da disciplina.

Fonte: Adaptação dos autores.

Segundo Hofstein, Aikenhead e Riquarts (1988, p. 358), no que diz respeito à educação CTS/CTSA, o ensino do conteúdo de ciências [e áreas de fronteiras] deve abranger o contexto do correspondente meio tecnológico e social, no qual os estudantes integram o conhecimento científico com a tecnologia e o mundo social de suas experiências do dia-a-dia. A proposta curricular da educação CTS/CTSA corresponderia, portanto, a uma integração entre educação científica, tecnológica e social [acrescentamos ambiental], em que os conteúdos científicos e 
tecnológicos são estudados juntamente com a discussão de seus aspectos históricos, éticos, políticos e socioeconômicos (LÓPEZ e CEREZO, 1996).

Santos (2007) ressalta que o conteúdo referente às ciências naturais dos currículos de CTS/CTSA é composto por aspectos relativos a estudos políticos de ciência, mais vinculados às questões sociais externas à comunidade científica (conservação de energia, crescimento populacional, efeitos da energia nuclear etc.) e a aspectos da ciência vinculados às questões internas à comunidade científica, relacionadas a sua epistemologia e filosofia (ROSENTHAL, 1989). Em nosso trabalho, buscamos debates conteúdos perpassando por diferentes aspectos tais como científicos, tecnológicos, culturais, sociais, econômicos, políticos, ambientais, além dos aspectos da saúde. Por exemplo, nos aspectos política - buscamos perpassar pelas interações entre a ciência e a tecnologia e os sistemas público, de governo e legal; a tomada de decisão sobre ciência e tecnologia; o uso político da ciência e tecnologia; ciência, tecnologia, defesa nacional e políticas globais. O diagrama mental aponta para uma diversidade de conteúdos/conceitos que demonstra a riqueza da prática pedagógica desenvolvida nesta perspectiva de ensino e aprendizagem. Neste caso, os seus conceitos chaves foram apresentados de maneiras claras e objetivas que possibilitou a compreensão, estimulação e ampliação de visão de mundo. Dessa forma, a assimilação de conteúdos mais abrangentes e conectados às questões locais/regionais promovem a ampliação de visão de mundo.

\subsection{Etapa III: Sistematizar}

Na Figura 5 está apresentado um mosaico contendo fotografias dos momentos da aula da disciplina de Segurança, Meio Ambiente e Saúde (SMS), no bloco de conteúdos destinado a parte de Segurança do Trabalho. No mosaico, percebe-se as anotações realizadas pelos estudantes nos cadernos escolares, que exibe o detalhamento na produção dos manuscritos. Em outra fotografia observa-se os momentos da oficina sobre equipamentos de proteção Individual, realizada com dois profissionais de uma empresa que fornece equipamentos para indústrias e empresas especializadas.

Com a finalidade de discutir ações de promoção de saúde, como conteúdo da gestão integrada de SMS, uma das atividades realizadas e apresentada no mosaico foi a Oficina de Primeiros Socorros, que contou com apoio do setor de enfermagem do campus. O material de referência utilizado na aula de campo foi o Manual de Primeiro Socorros do Núcleo de Biossegurança da Fundação Oswaldo Cruz (FIOCRUZ, 2003). Para Gomes et al. (2011), as práticas de educação em saúde apresentam grande relevância para a prevenção de doenças e promoção de saúde. $\mathrm{O}$ aprendizado produzido em ações pedagógicas combinadas às práticas de 
saúde, como as que abrangem as noções básicas de primeiros socorros, possibilitam maior argumentação crítica dos estudantes, favorecendo o desenvolvimento de medidas benéficas para a saúde como a prevenção dos acidentes e o salvamento de vidas (GOMES et al., 2011).

Conforme apresentado no mosaico (Figura 5), aulas de demonstração EPI também foram realizadas com o objetivo de estudar as legislações e práticas de prevenção de acidentes de trabalho, bem como propiciar reflexões sobre as práticas que propiciam a incorporação dos EPI nas rotinas dos trabalhadores. Na ocasião, os estudantes estudaram as noções básicas de atendimento de primeiros socorros, como a avaliação do local do acidente, a proteção do acidentado e a avaliação de funções e sinais vitais. Práticas de simulação de socorro e salvamento foram realizadas com uso de equipamentos e recursos disponibilizados pelo setor de enfermagem, como ataduras e macas, entre outros. Realizou-se práticas de massagem cardíaca externa, posicionamento em casos de estado de choque (hipovolêmico, cardiogênico, septicêmico e anafilático), imobilização de fraturas e ressuscitação cardiorrespiratória.

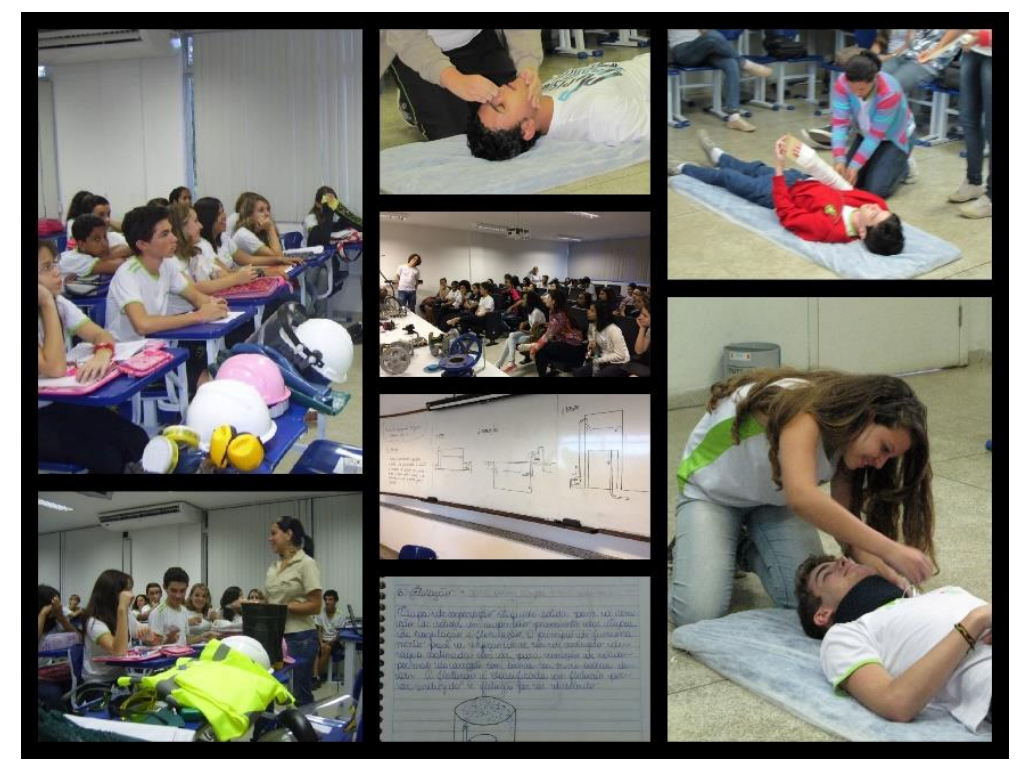

Figura 5 - Mosaico contendo fotografias dos momentos da aula da disciplina de Segurança, Meio Ambiente e Saúde, no bloco de conteúdos destinado a parte de Segurança do Trabalho.

Fonte: Adaptação dos autores. 
Segundo Neves (2011), a baixa adesão ao uso dos equipamentos de proteção individual e o seu manuseio incorreto são decorrentes de fatores como desconforto, incômodo, descuido, esquecimento, falta de hábito, inadequação dos equipamentos, quantidade insuficiente e, principalmente, falta de conhecimento e descrença quanto ao seu uso. Para a autora, a adesão ao uso de equipamentos de proteção está intimamente relacionada à percepção que os profissionais têm acerca dos riscos a que estão expostos e da susceptibilidade a esses riscos (NEVES, 2011). Nessas aulas, foram apresentadas diversas categorias de EPI, como máscaras faciais, com e sem respiradores, luvas, aventais, coletes, capacetes e botas, bem como alguns Equipamentos de Proteção Coletiva (EPC). Na ocasião, foram apresentadas informações sobre o Certificado de Aprovação dos EPI, expedido pelo Ministério do Trabalho e Emprego, bem como os prazos de validade dos equipamentos e suas aplicações. Durante as aulas, os estudantes puderam simular condições de uso dos EPI, comparar as particularidades e especificidades de cada item, contar suas experiências e sensações propiciadas pelo uso dos equipamentos e realizar registros fotográficos.

Em outro momento, foi realizada uma palestra por um profissional - Técnico em Mecânica, que apresentou de forma contextualizada algumas práticas seguras na operação de sistemas pneumáticos e hidráulicos. Durante a apresentação, os estudantes puderam conhecer o funcionamento de diversos atuadores eletrônicos e pneumáticos, além de estudarem sobre os riscos de acidentes presentes no uso da eletricidade utilizada para funcionamento desses sistemas. Apresentou-se um detalhamento sobre a instalação e manuseio de bombas e geradores elétricos, além de discussões sobre possibilidades de lesões físicas na operação de componentes que exigem grandes esforços físicos, como as válvulas de controle de fluxo hidráulico. Neste sentido, os estudantes puderam realizar manobras controladas visando aplicar os conhecimentos sobre práticas seguras e preventivas, acompanhadas por anotações sobre os conteúdos discutidos e problematizados para servirem como referencial para realização das próximas etapas. Sempre que possível, sob orientação do professor, os estudantes produziam relatos orais e escritos nos quais expressavam uma síntese cognitiva sobre os conteúdos apropriados durante a práticas pedagógica, incluindo diversas questões-problemas.

\subsection{Etapa IV: Produzir}

Na Figura 6 está evidenciado um mosaico de fotografias produzidas durante uma aula de campo realizada numa estação de tratamento de água. Nesta etapa, o professor quase sempre realizava uma aula de campo numa estação de tratamento de água para aprofundar a discussão sobre alguns conceitos trabalhados anteriormente, como por exemplo riscos físicos, químicos, 
biológicos, acidentes de trabalhos e formas de prevenção e, ao mesmo tempo, se introduzia o próximo módulo do curso que tratava das questões ambientais. Do ponto de vista metodológico, o objetivo desta etapa era o de evidenciar e potencializar a superação das ideias iniciais e a elaboração de sínteses cognitivas por meio de diferentes linguagens e aplicação de diversas atividades.

A participação dos estudantes na intervenção pedagógica foi por meio da produção de dados a partir de observações, anotações e investigações sobre o conteúdo programático trabalhado anteriormente a essa etapa, o que se constituiu numa forma de mediação pedagógicadialética.

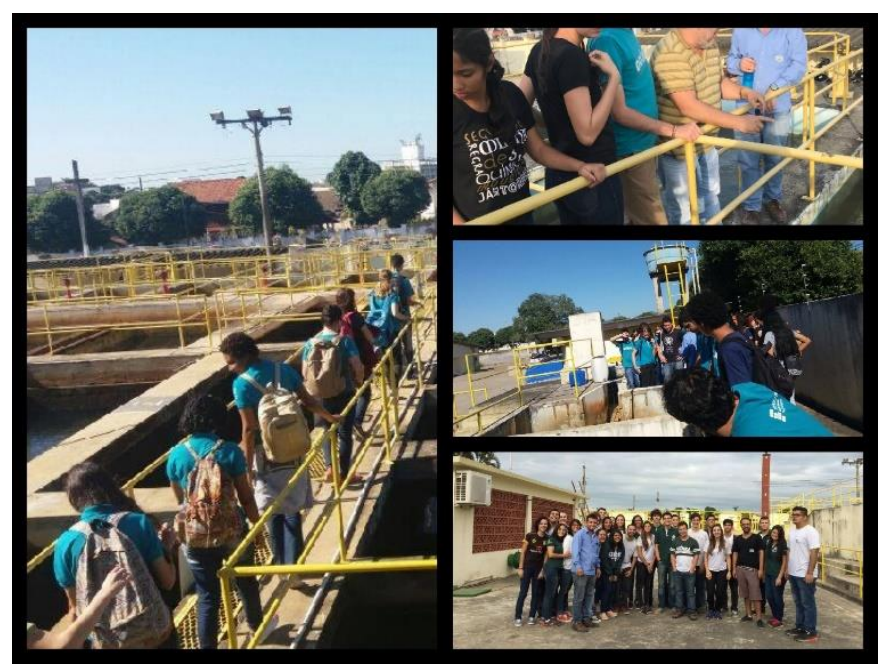

Figura 6 - Mosaico contendo fotografias dos momentos da aula da disciplina de Segurança, Meio Ambiente e Saúde, durante a aula de campo realizada numa estação de tratamento de água. Fonte: Adaptação dos autores.

Ao desenvolver uma prática educativa pautada na Metodologia de Mediação Dialética, destacam-se as atividades cognitivas necessárias à produção de modos de ver o mundo com base na e como produto da atividade que privilegie os atos de analisar, antecipar, classificar, comparar, comprovar, concluir, criticar, prever, provar e sintetizar. Como consequência, Correia e Carvalho (2012), ao discutir o conceito de sociedade, cuja a raiz etimológica do termo, sociedade vem do latim societas, que está relacionado ao ato de ser companheiro, do termo latim cumpanere, designando aquele com quem se come do mesmo pão, ressaltam que valora as suas relações, dando-lhe sentido ético e intencionalidade, algo que é próprio do humano, e complementa:

[...] o único ser portador do privilégio de vivenciar o processo de educabilidade, pois nasce cem por cento dependente, desenvolve-se gradativamente e, graças à educação, alcança a relativa autonomia característica dos seres racionais, fazendo esse percurso ontoexistencial incrustado no contexto cultural simbólico, apreendendo, na vida e na escola, o modo humano de ser no mundo e no papel de homem ou de mulher (CORREIA e CARVALHO, 2012). 
Nos trechos das falas coletadas durante as aulas sobre EPI e Normas Regularizadoras lecionadas no primeiro semestre dos anos de 2011 e 2013 às turmas de $1^{\circ}$ ano do curso técnico em química integrado ao ensino médio dos turnos matutino e vespertino evidenciam o diálogo estabelecido entre professor e estudantes a partir de alguns questionamentos, conforme o quadro 04.

Quadro 04 - Trechos das falas coletadas durante uma das aulas sobre EPI e Normas Regularizadoras que evidenciam o diálogo estabelecido entre professor e estudantes a partir de alguns questionamentos.

\begin{tabular}{|c|c|c|c|}
\hline Questão & Trecho de Fala & Turma & $\begin{array}{c}\text { Quantidade } \\
\text { de Alunos }\end{array}$ \\
\hline \multirow{5}{*}{$\begin{array}{l}\text { [...] sobre os } \\
\text { Equipamentos de } \\
\text { Proteção Individual } \\
\text { (EPI) o que } \\
\text { aprendeu sobre a } \\
\text { disciplina? Cite um } \\
\text { momento } r \text { que } \\
\text { marcou nua } \\
\text { formação nesse } \\
\text { assunto (EPI). Os } \\
\text { estudantes ras } \\
\text { responderam as } \\
\text { questões utilizando } \\
\text { um formulário } \\
\text { digital, hospedado } \\
\text { em um sítio na } \\
\text { internet. }\end{array}$} & $\begin{array}{l}\text { Estudante } 13-[\ldots] \text { que é importante para garantir a integridade } \\
\text { física do trabalhador. É obrigação da empresa fornecê-lo e do } \\
\text { empregado fazer o uso correto desses equipamentos. Se não me } \\
\text { engano, cada EPI possui um certificado e até data de validade [...]. }\end{array}$ & $\begin{array}{c}2011 \text { - } \\
\text { Matutino }\end{array}$ & 32 \\
\hline & $\begin{array}{l}\text { Estudante } 09 \text { - [...] é definido por uma Norma Regulamentadora, e } \\
\text { são responsáveis pela proteção e integridade do indivíduo com a } \\
\text { intenção também de minimizar os riscos do ambiente de trabalho e } \\
\text { evitar os acidentes e doenças ocupacionais" }\end{array}$ & $\begin{array}{c}2011 \text { - } \\
\text { Vespertino }\end{array}$ & 41 \\
\hline & $\begin{array}{l}\text { Estudante } 07-[\ldots] \text { são muito importantes para evitar lesões graves } \\
\text { nos acidentes de trabalho. Devemos sempre usar EPI, } \\
\text { independentemente da situação". }\end{array}$ & $\begin{array}{c}2012 \text { - } \\
\text { Matutino }\end{array}$ & 36 \\
\hline & $\begin{array}{l}\text { Estudante } 10-[. . .] \text { aprendi a importância do EPI, tanto pro } \\
\text { rendimento e funcionamento da empresa, quanto pro funcionário. } \\
\text { [...] aprendi [sobre] a obrigatoriedade e as leis que rodeiam o uso } \\
\text { do mesmo. E também aprendi [sobre] os EPI mais usados, } \\
\text { principalmente na minha área de atuação, que é o técnico em } \\
\text { química. }\end{array}$ & $\begin{array}{c}2012- \\
\text { Vespertino }\end{array}$ & 40 \\
\hline & $\begin{array}{l}\text { Estudante } 10-[\ldots] \text { que o uso deles é de suma importância para a } \\
\text { proteção do indivíduo no trabalho. Além de apenas } \\
\text { disponibilizarem esses equipamentos, é muito importante falar da } \\
\text { importância do uso deles no ambiente de trabalho para os } \\
\text { funcionários, pois muitos não utilizam e não tem noção do risco que } \\
\text { estão correndo [...]. }\end{array}$ & $\begin{array}{c}2013 \text { - } \\
\text { Vespertino }\end{array}$ & 45 \\
\hline
\end{tabular}

Fonte: Adaptação dos autores.

Os diálogos estabelecidos nos momentos do campo [e pós-campo] enfatizam o processo de descoberta e conexões que os estudantes estabeleceram a partir da intervenção pedagógica. Nesta aula, por exemplo, o professor analisou as respostas comparando-as com a produção da primeira etapa, visando verificar se houve superação das ideias iniciais dos estudantes no conceito elaborado. A análise indicou que houve superação do conhecimento prévio, razão pela qual a etapa de "Produzir" tornou-se imediatamente um novo ponto de partida.

De acordo com Teixeira (2003), no campo da pesquisa didática associada ao ensino de ciências, algumas críticas também têm sido desenvolvidas e as inovações propostas têm gerado avanços modestos, para não dizer incipiente, na realidade escolar brasileira. O autor, enfatizando o movimento CTS/CTSA articulado à perspectiva da Pedagogia Histórico-Crítica, 
proposta por Demerval Saviani, ressalta que o movimento CTS/CTSA na educação busca-se defender a existência de propostas educacionais que se orientam por princípios democráticos e emancipadores, articulados aos interesses populares, os quais subsidiam os projetos para a construção de um ensino de ciências em sintonia com movimentos pedagógicos com vistas ao processo de democratização do saber sistematizado, a partir da compreensão da realidade histórica e dos problemas sociais. Neste sentido, o autor identificou pontos de convergência entre o Movimento CTS/CTSA e a perspectiva da Pedagogia Histórico-Crítica.

Numa perspectiva Freiriana, Rocha e Leite (2017) também produziram uma prática de aula de campo com enfoque CTS/CTSA, envolvendo aluno do ensino fundamental para conhecerem a realidade da comunidade pesqueira, a qual englobava a escola onde se desenvolveu a intervenção. A partir do estudo realizado sobre a prática escolar, os autores identificaram que houve a articulação de saberes escolares, populares e científicos a partir das temáticas de "manguezal", "pesca artesanal" e "sustentabilidade", perpassando por conteúdos de ciências naturais, aspectos tecnológicos, sociocientíficos, socioeconômicos, sócio históricos, socioculturais e socioambientais. De acordo com Correa e Bazzo (2017), as práticas de CTS/CTSA realizada na perspectiva de uma educação emancipadora, isto é, perpassando pela concepção, formação e atitude, que têm o papel de criar espaços, por meio do diálogo, de reflexões, de questionamentos, de poder decisório sobre as ações e soluções construídas coletivamente, possibilita ao cidadão reconhecer que está envolvido socialmente e lutar com mais consciência pela promoção de ambientes de trabalho que motivem a cooperação, a humanização e o posicionamento crítico em relação ao processo civilizatório.

Saul (2014), ao escrever sobre as práticas de Paulo Freire no sudeste do Brasil, também identificou características semelhantes nas práticas escolares, tais como adoção de política curricular participativa e democrática, produção de um trabalho coletivo que respeitou o saber de experiência feito de estudantes e professores, e a valorização do processo de ensinoaprendizagem dialógico, na perspectiva de construção de uma autonomia curricular compartilhada. Foi nesta perspectiva que buscamos desenvolver a formação dos técnicos de nível médio, discutido no presente artigo.

Os trechos de falas coletadas durante as aulas sobre EPI, ocorridas no primeiro semestre dos anos de 2014 a 2016, evidenciam o diálogo estabelecido entre professor e estudantes a partir da provocação, conforme o quadro 05. Novamente, o professor analisou as respostas comparando-as com a produção da primeira etapa, também visando saber se houve superação das ideias iniciais dos estudantes no conceito elaborado. A análise demonstrou que houve superação das ideias concebidas previamente, razão pela qual a etapa de "Produzir" tornou-se imediatamente um novo ponto de partida. Os estudantes demonstraram que a 
metodologia se materializou nos processos pedagógicos desenvolvidos durante a intervenção pedagógica.

Quadro 05 - Trechos das falas coletadas durante uma das aulas sobre EPI que evidenciam o diálogo estabelecido entre professor e estudantes a partir de provocações.

\begin{tabular}{|c|c|c|c|}
\hline Questão & Trecho de Fala & Turma & $\begin{array}{l}\text { Quantidad } \\
\text { e de Alunos }\end{array}$ \\
\hline \multirow{4}{*}{$\begin{array}{l}\text { Professor: - [...] cite um } \\
\text { momento que marcou sua } \\
\text { formação nesse assunto } \\
\text { (EPI), que trata da } \\
\text { recordação de momentos } \\
\text { importantes das práticas } \\
\text { sobre os EPI. }\end{array}$} & $\begin{array}{l}\text { Estudante } 04-[. . .] \text { quando estava aprendendo o que me marcou } \\
\text { muito foram fotos e complicações causadas pela falta do uso dos } \\
\text { EPI. Comecei a ter outro olhar sobre o assunto. }\end{array}$ & $\begin{array}{c}2014 \text { - } \\
\text { Matutino }\end{array}$ & 48 \\
\hline & $\begin{array}{l}\text { Estudante 02 - [...] uma das coisas que me marcou é que o uso } \\
\text { destes equipamentos está diretamente ligado às boas práticas do } \\
\text { processo de produção, interferindo inclusive no desempenho dos } \\
\text { empregados, já que uma boa saúde é um fator que interfere } \\
\text { diretamente no desempenho. Outra coisa que marcou foi uma } \\
\text { visita técnica a Estação de Tratamento de água e esgoto de } \\
\text { Aracruz em que podemos ver na prática e inclusive usar alguns } \\
\text { EPI. }\end{array}$ & $\begin{array}{c}2015 \text { - } \\
\text { Matutino }\end{array}$ & 45 \\
\hline & $\begin{array}{l}\text { Estudante } 05-[\ldots] \text { os acidentes de trabalho relatados nas aulas, } \\
\text { que poderiam terem sido evitados com o simples uso de EPI. Nas } \\
\text { aulas práticas também, quando ocorria pequenos incidentes, } \\
\text { sempre me remetia às aulas de SMS e a importância do EPI. }\end{array}$ & $\begin{array}{l}2015- \\
\text { Vespertin } \\
\quad o\end{array}$ & 41 \\
\hline & $\begin{array}{l}\text { Estudante } 08-[\ldots] \text { Um momento que lembro é uma aula que o } \\
\text { professor passou uma série de vídeos, em que o personagem } \\
\text { principal sempre "morria" em decorrência do mau uso ou } \\
\text { ausência de EPIs em diversos ambientes de trabalho. }\end{array}$ & $\begin{array}{l}2016- \\
\text { Vespertin } \\
\quad o\end{array}$ & 44 \\
\hline
\end{tabular}

Fonte: Adaptação dos autores.

De acordo com Auler e Bazzo (2001), entre os objetivos do movimento CTS/CTSA na educação, abrange promover o interesse dos estudantes em relacionar a ciência com as aplicações tecnológicas e os fenômenos da vida cotidiana, abordar o estudo daqueles fatos e aplicações científicas que tenham uma maior relevância social, abordar as implicações sociais e éticas relacionadas ao uso da ciência e da tecnologia e adquirir uma compreensão da natureza da ciência e do trabalho científico.

Considerando a combinação de aspectos metodológicos da mediação dialética com a educação CTS/CTSA, na perspectiva freiriana, produziu-se uma prática pedagógica que evoluiu gradativamente de 2011 a 2016, agregando procedimentos pedagógicos pautados na coletividade, produção colaborativa de conhecimento, ênfase na prática social, articulando ciência e tecnologia com aspectos locais e regionais. Vale citar que, durante 2011 a 2016, nem todas as vezes a prática se constituiu como sendo uma situação de sucesso. Nesse caso, às vezes para alguns estudantes, cabe o Resgatar, para os casos em que a análise demonstre que não houve superação. Neste caso, o professor deve planejar novamente a prática educativa. 


\section{CONCLUSÃO}

A MMD apresentada neste trabalho possibilitou abordar os conteúdos da segurança do trabalho dialogadas com o ensino médio, considerando o contexto da educação profissional de nível médio. A análise metodológica evidenciou que a prática pedagógica perpassou pelas etapas de resgatar, problematizar, sistematizar e produzir. Adicionalmente, promoveu a intersetorialidade, uma vez que possibilitou que a parceria entre o locus de formação (Escola Técnica) com o mundo do trabalho.

Considerando a combinação de aspectos metodológicos da mediação dialética com a educação CTS/CTSA, na perspectiva freiriana, produziu-se uma prática pedagógica que evoluiu gradativamente de 2011 a 2016, agregando procedimentos pedagógicos pautados na coletividade, produção colaborativa de conhecimento, ênfase na prática social, articulando ciência e tecnologia com aspectos locais e regionais.

A análise do desenvolvimento da intervenção pedagógica demonstrou as potencialidades para abordagem de conteúdos programáticos previstos nas disciplinas como também produzir conexões para além da sala de aula, inclusive com o mundo do trabalho. Nesta seara de discussões, foi possível perpassar por aspectos dos riscos, acidentes do trabalho, da prevenção de acidentes industriais, equipamento de produção individual, entre outros, o que possibilitou o diálogo entre os saberes epistemológicos e as suas aplicações nas diversas situações reais ligadas ao cotidiano escolar e profissional, fundamentais para o desenvolvimento integral do indivíduo, da sua autonomia e da sua criticidade.

A intervenção pedagógica analisada pela ótica da Metodologia de Mediação Dialética articulada à perspectiva do movimento CTS/CTSA, realizada na perspectiva de uma educação emancipadora freiriana, permitiu desenvolver uma prática que perpassou pela concepção, formação e atitude, que teve o papel de criar espaços, por meio do diálogo, de reflexões, de questionamentos, de poder decisório sobre as ações e soluções construídas coletivamente. Considerando a perspectiva da formação para o mundo do trabalho, a prática pedagógica também possibilitou ao cidadão reconhecer que está envolvido socialmente e lutar com mais consciência pela promoção de ambientes de trabalho que motivem a cooperação, a humanização e o posicionamento crítico em relação ao processo civilizatório.

\section{AGRADECIMENTOS}

Os autores agradecem ao Programa de Pós-graduação em Educação em Ciências e Matemática do Ifes, ao CNPq e a Fapes pelo apoio concedido no desenvolvimento do projeto de pesquisa. 


\section{REFERÊNCIAS}

AIKENHEAD, G. S. Educação Científica para todos. Tradução de Maria Teresa Oliveira. 1a. Edição. Mangualde - PT: Edições Pedagogo. 2009.

AIKENHEAD, G. S. Toward a First Nations Cross-Cultural Science and Technology Curriculum. Science Education, v. 81, n. 2 p. 217-238, Apr., 1997.

ALMEIDA, Patrícia Cristina Albieri de; BIAJONE, Jefferson. Saberes docentes e formação inicial de professores: implicações e desafios para as propostas de formação. Educação e Pesquisa, v. 33, n. 2, p. 281-295, 2007.

ARNONI, Maria Eliza Brefere. Mediação dialético-pedagógica e práxis educativa: o aspecto ontológico da aula. Revista Educação e Emancipação, São Luís/ MA, v.5, n.2, jul/dez. 2012.

AULER, Décio; BAZZO, Walter Antonio. Reflexões para a implementação do movimento cts no contexto educacional brasileiro. Ciência \& Educação, v.7, n.1, p.1-13, 2001.

AULER, Décio; BAZZO, Walter Antonio. Reflexões para a implementação do movimento CTS no contexto educacional brasileiro. Ciência \&. Educação, v.7, n.1, p.1-13, 2001.

BRASIL. Catálogo Nacional de Cursos Técnicos. Secretaria de Educação Profissional e Tecnológica. Ministério da Educação. $3^{\text {a }}$. Edição. Brasília: Ministério da Educação. 2016. 290 p.

BRASIL. Educação Profissional Técnica de Nível Médio integrada ao Ensino Médio. Secretaria de Educação Profissional e Tecnológica. Ministério da Educação. Brasília/DF. 2007.

BRASIL. Lei de Diretrizes e Bases da Educação Nacional. Lei Federal No. 9394, de 20 de dezembro de 1996. Brasília, DF. 1996.

BRASIL. Lei n. 8.213, de 24 de julho de 1991. Dispõe sobre os Planos de Benefícios da Previdência Social e dá outras providências. Brasília, DF, 1991.

BRASIL. Orientações Curriculares Nacionais para o Ensino Médio. Volume 2. Ciências da Natureza, Matemática e suas tecnologias. Ministério da Educação. Secretaria de Educação Média e Tecnológica. Brasília: MEC, 2006. 140 p.

BRASIL. Parâmetros Curriculares Nacionais (Ensino Médio). Ministério da Educação. Secretaria de Educação Média e Tecnológica. Brasília: MEC, 2000.

BRASIL. Parâmetros Curriculares Nacionais: Terceiro e quarto ciclos: apresentação dos temas transversais. Ministério da Educação. Brasília: Secretaria de Ensino Fundamental. 1998. 
CAETANO, Athyla; LEITE, Sidnei Quezada Meireles; ROSA, Caroline Azevedo. Educação em saúde na escola: plano de intervenção escolar para debater infecções sexualmente transmissíveis no ensino médio. Experiências em Ensino de Ciências. v.12, No.8. pp. 227238, 2017.

CORREA, Luciana Flôr Correa; BAZZO, Walter Antonio. Contribuições da Abordagem Ciência, Tecnologia e Sociedade para a Humanização do Trabalho Docente. Contexto \& Educação. Ano 32, no 102, Maio/Ago. 2017.

CORREIA, Wilson; CARVALHO, Iolanda. Práxis educativa: tempo, pensamento e sociedade. Revista Portuguesa de Educação, 25(2), pp. 63-87, 2012.

DELIZOICOV, Demétrio. Angotti, José André. Pernambuco, Martha Maria. Ensino de ciências: fundamentos e métodos. 1a. Edição. São Paulo: Editora Cortez. 2002. 364 p. DOMINGUES, J.L.; TOSCHI, N.S.; OLIVEIRA, J.F. A reforma do Ensino Médio: a nova formulação curricular e a realidade da escola pública. Educação \& Sociedade, 21(70). pp. 63-79. 2000.

FIOCRUZ. Manual de Primeiros Socorros. Núcleo de Biossegurança. Ministério da Saúde. Rio de Janeiro: Fundação Oswaldo Cruz. 2003. 170 p.

FREIRE, Paulo. Pedagogia da autonomia: saberes necessários à prática educativa. Editora Paz e Terra. São Paulo, 2004.

FREIRE, Paulo. Pedagogia da esperança: um reencontro com a pedagogia do oprimido. 17 edição. São Paulo: Editora Paz e Terra, 2011.

FREIRE, Paulo. Pedagogia do oprimido. 40 Edição. Rio de Janeiro: Paz e Terra. 2005. 213 p.

GIL, Antonio Carlos. Estudo de Caso. São Paulo: Atlas, 2009. 148 p.

GIL, Antonio Carlos. Métodos e técnicas de pesquisa social. Sexta edição. São Paulo: Atlas, 2014. 200 p.

GOMES, Ludmila Mourão Xavier; SANTOS, Christiano Almeida; MENDES, Marta Raquel. al. Análise do conhecimento sobre primeiros socorros de professores de escolas públicas.

Cadernos de Ciência e Saúde. Enfermagem e Farmácia. Montes Claros, Faculdades Santo Agostinho, v. 1, n. 1, p. 57-64, 2011.

HOFSTEIN, A., AIKENHEAD, G., RIQUARTS, K. Discussions over STS at the fourth IOSTE symposium. International Journal of Science Education, v. 10, n. 4, p.357-366. 1988.

IFES. Projetos Pedagógico do Curso Técnico em Química [integrado ao Ensino Médio]. Instituto Federal do Espírito Santo. Campus Aracruz. 2009. 
KRAUS, Lalita; EGLER, Tamara; COSTA, Aldenilson. Educação em rede: por uma pedagogia contextualizada e imanente. Dialnet. v.9 No 1, pp 79-105, 2017.

LÓPEZ, J. L. L.; CEREZO, J. A. L. Educación CTS en acción: enseñanza secundaria y universidad. In: GARCÍA, M. I. G., CEREZO, J. A. L., LÓPEZ, J. L. L. Ciencia, tecnología y sociedad: una introducción al estudio social de la ciencia y la tecnología. Madrid: Editorial Tecnos S. A. 1996.

MAESTRELLI, Sylvia Regina Pedrosa; Torres, Juliana Rezende. Abordagem temática freireana: uma concepção curricular para a efetivação de atributos da educação ambiental escolar. Revista e-Curriculum, São Paulo, n. 12 v. 02, maio/out. 2014.

NEVES, Heliny Carneiro Cunha et al. Segurança dos trabalhadores de enfermagem e fatores determinantes para adesão aos equipamentos de proteção individual. Revista LatinoAmericana de Enfermagem, v. 19, n. 2, p. 354-361, 2011.

ROCHA, Katiuscia Soares Viana; LEITE, Sidnei Quezada Meireles. Uma prática de educação ambiental para discutir sustentabilidade no manguezal de Nova Almeida do Estado do Espírito Santo. Ensino, Saúde e Ambiente - v.10 (1), pp. 218-237, Abril. 2017.

ROSENTHAL, D. B. Two approaches to science - technology - society (STS) education. Science Education, v. 73, n. 5, p.581-589. 1989.

SANTOS, Wildson Luiz Pereira dos; AULER, Décio. CTS e educação científica: desafios, tendência e resultados de pesquisas. Brasília: Editora Universidade de Brasília, 2011. SANTOS, Wildson Luiz Pereira. Contextualização no ensino de ciências por meio de temas CTS EM uma perspectiva crítica. Ciência \& Ensino. v.1, número especial. 2007. SAUL, Ana Maria. Políticas e práticas educativas inspiradas no pensamento de Paulo Freire: pesquisando diferentes contextos. Currículo sem Fronteiras, v. 14, n. 3, pp. 129-142, set/dez 2014.

SOLINO, Ana Paula; GEHLEN, Simoni Tormöhlen. Abordagem temática freireana e o ensino de ciências por investigação: possíveis relações epistemológicas e pedagógicas. Investigações em Ensino de Ciências. V.19(1), pp. 141-162. 2014.

TEIXEIRA, Paulo Marcelo M. A educação científica sob a perspectiva da pedagogia Histórico-Crítica e do movimento C.T.S. no ensino de ciência. Ciência \& Educação, v. 9, n. 2, p. 177-190, 2003.

VIEIRA, Josimar Aparecido; VIEIRA, Marilandi Maria Mascarello. Formação integrada do ensino médio com a educação profissional: o que dizem as pesquisas. Revista Thema. Volume 13. No. 1. p. 79-92. 2016. 


\section{SOBRE OS AUTORES}

FELIPE SARMENGHI RANGEL. Professor Efetivo do Instituto Federal do Espírito Santo. Engenheiro Químico e Especialista em Engenharia Sanitária e Ambiental. Mestrando do Programa de Pós-graduação em Educação em Ciências e Matemática do Instituto Federal do Espírito Santo (Educimat/Ifes). Planejou e aplicou a intervenção pedagógica. Organizou os dados coletados em atividades pedagógicas. Analisou de forma colaborativa os aspectos metodológicos e sociofilosóficos da educação CTS/CTSA.

JÉSSICA CRISTINA SILVA DELCARRO. Possui Licenciatura em Ciências Biológicas pela Universidade Federal do Espírito Santo. Mestranda do Programa de Pós-graduação em Educação em Ciências e Matemática do Instituto Federal do Espírito Santo (Educimat/Ifes). Organizou os dados coletados em ordem cronológica e de atividades pedagógicas. Analisou de forma colaborativa os aspectos metodológicos e sociofilosóficos da educação CTS/CTSA.

SIDNEI QUEZADA MEIRELES LEITE. Professor Titular do Instituto Federal do Espírito Santo. Professor permanente do Programa de Programa de Pós-graduação em Educação em Ciências e Matemática do Instituto Federal do Espírito Santo. Possui Licenciatura em Química e Bacharelado em Engenharia Química pela UFRJ. Possui Doutorado em Engenharia Química pela Coppe/UFRJ. Possui Estágio Pós-doutoral em Educação pela UnB e Universidade de Aveiro-Portugal. Auxiliou no planejamento das atividades, orientou quanto ao embasamento teórico, análise dos dados e discussão dos resultados. 